\title{
Формирование колористики северных городов
}

\author{
Е.В.Гонтарь, САФУ им. М.В. Ломоносова, Архангельск \\ М.А.Туробова, САФУ им. М.В. Ломоносова, Архангельск \\ М.А.Фролова САФУ им. М.В. Ломоносова, Архангельск
}

Условия формирования жилой застройки в северных городах достаточно специфичны. На их территории имеется значительное количество зданий, построенных по типовым проектам, которые не учитывают негативных природно-климатических факторов северных территорий. Для таких городов необходимо создавать особые условия окружающей архитектурной среды, в том числе разрабатывать особенные цветовые решения. Роль цвета в жизни человека и в восприятии им пространства достаточно велика, поэтому цветовые решения, используемые в архитектуре, имеют существенное значение. В работе на примере Архангельска проведён анализ факторов колористики, оказывающих влияние на цветовую среду северного города, а также выявлена необходимость комплексного подхода к учёту факторов колористики при формировании цветовых решений зданий. Для исследования была выбрана натуральная система цвета NCS (Natural Color System) как наиболее распространенная среди архитекторов и дизайнеров и более естественная для восприятия её человеком. В ходе проведённого исследования установлены наиболее благоприятные цветовые решения при оформлении фасадов зданий в условиях городской конгломерации северных территорий. Внедрение разработанных колористических решений для Архангельска целесообразно для обособленного района города, на территории которого ведётся активная застройка. Сделан вывод о необходимости корректировки цветовых решений ограждающих конструкций фасадов существующих зданий. Предложенные варианты формирования и корректировки цветовой среды северного города на примере Архангельска способствуют наиболее гармоничному цветовому оформлению города, улучшают окружающую среду в целом, что положительно сказывается на психологическом состоянии горожан.

Ключевые слова: гармоничная цветовая среда, колористика, северные территории, Архангельск.

\section{The Formation of Coloristics of the Northern Cities \\ E.V.Gontar, NArFU, Arkhangelsk \\ M.A.Turobova, NArFU, Arkhangelsk \\ M.A.Frolova. NArFU, Arkhangelsk}

In northern cities conditions of the formation of residential buildings are quite specific. There are a significant number of buildings built according to standard projects that do not consider the negative natural and climatic factors of the northern territories. For such cities, it is necessary to create special conditions for the architectural environment, including special color solutions. The role of color in a person's life and perception of space is quite large, therefore the color solutions used in architecture are essential. The factors of coloristic influence on the color environment of the northern city by the example of Arkhangelsk are analyzed in the paper. The need for a comprehensive approach to the calculation of color factors in the formation of color solutions of buildings also identified. For the study, the natural color system NCS (Natural Color System) was chosen as the most common among architects and designers and natural for human perception. In the course of the study, the most favorable color solutions for the design of building facades in the urban conglomeration of the northern territories were established. The implementation of the developed coloristic solutions for Arkhangelsk is advisable for a particular district of the city where active development takes place. The conclusion about the need to adjust the color solutions for the enclosing structures of the facades of existing buildings is made. The proposed options for the formation and correction of the northern city color environment on the example of Arkhangelsk contribute to the most harmonious color city design and improve the living comfort which positively influences the psychological condition of citizens.

Keywords: harmonious color environment, coloristic, northern territories, Arkhangelsk.

Чрезмерные информационные, психологические нагрузки и ряд социальных факторов негативно сказываются на состоянии здоровья человека, на которое влияют также сложные природно-климатические условия региона проживания, монотонность ландшафта и однотипность архитектурных форм [1]. Вариантом снижения влияния негативных факторов окружающей среды на эмоциональное самочувствие горожанина является внедрение в практику способов гармонизации пространства путём цветового воздействия.

В настоящее время доказана роль цвета в жизни человека [2; 3] и в восприятии им пространства, поэтому цветовые решения, используемые в архитектуре, имеют существенное значение. Цвет является средством придания живописности улицам города, также это показатель качества городской среды и её пригодности для проживания, значимый социальный фактор, поскольку колористические решения формируют средовую гармонию [4]. Выявлена высокая объединяющую роль цвета в городской среде, признана 
необходимость регулирования цветовых палитр в северных поселениях [5].

Всё вышеперечисленное в полной мере должно учитываться при строительстве или развитии городов и посёлков на северных территориях.

Из-за суровых климатических условий и зимнего пейзажа северяне, как правило, отдают предпочтение спокойным светлым тонам, цветам, приближенным к природным, которые ассоциируются у них с теплом и солнечным светом [6].

Важным, на наш взгляд, является создание гармоничной цветовой среды городской застройки путём реализации не только новых решений, но и сохранения облика существующих зданий. Нельзя не отметить значимость сохранения фасадов от воздействия загрязняющих веществ и пыли, находящихся в воздухе, в условиях их эксплуатации на территории северных городов при высокой влажности. Так, например, для территории города Архангельска характерна деревянная застройка (либо блочная и кирпичная с содержанием значительного объёма деревянных элементов). Поэтому одной из основных проблем при длительной эксплуатации таких конструкций является их деградация, происходящая в основном из-за грибкового поражения древесины. Ситуация с каменными зданиями также осложняется процессами, связанными с гниением деревянных свай, ростверков, лежней, балок перекрытий и конструкций крыш [7].

Проблемным моментом в вопросе сохранения зданий является состояние ограждающих конструкций - фасадов, а также их гармонизация с окружающей средой. В связи с этим целесообразно применять на практике различные типы защитных покрытий, которые должны обладать антибиодиструктивными, противопожарными, влагоустойчивыми свойствами и иметь цветовую гамму, гармонирующую с окружающей исторической и современной застройкой территории [8; 9].

Следует отметить, что в настоящее время многие здания в северных городах, например в Архангельске, построены по типовому проекту. В основном эти проекты не учитывают негативные особенности северных природно-климатических условий: недостаток тепла и света, напряжённый иономагнитный режим, резкие колебания климатических параметров [10]. Поэтому в качестве объекта исследований нами была выбрана именно эта городская конгломерация.

Целью проведённых исследований является анализ особенностей формирования гармоничной цветовой среды северного города на примере Архангельска и разработка для него цветовой палитры.

Разработка цветовых решений произведена в следующей последовательности: районная планировка, генеральный план, проект детальной планировки, проект застройки, рабочее проектирование. Выбор обусловлен рядом исследований, представленных в источниках ${ }^{1}$ [11].

В ходе разработки цветовых решений проведён анализ всех четырёх факторов колористики: природно-климати-

${ }^{1}$ Методика проектирования колористики города [Электронный ресурс]. - Режим доступа: https://life-prog.ru/1_809_metodika-proektirovaniyakoloristiki-goroda.html (дата обращения 01.07.2018). ческих условий, исторической архитектурной полихромии, цветовой культуры общества, городской структуры [12].

Формирование колористической среды города во многом зависит от природного окружения. Цветовая картина природного, а значит и городского ландшафтов в целом зависит от множества компонентов: климатических условий, температурного режима, осадков в виде дождя и снега, флоры, морфологических особенностей территории и солнечного сияния.

Большое значение также имеет принадлежность архитектурной полихромии к исторической или современной архитектуре. Один из важных вопросов в полихромии районов городов - цветовое звучание отдельных историкоархитектурных памятников.

Рассматривая цветовые предпочтения людей как части цветовой культуры, можно увидеть уровень её развития. При этом предпочтения являются своеобразным двигателем развития цветовой культуры [13]. Нужно отметить, что социально-культурные факторы постоянно претерпевают изменения.

Определение того или иного типа структуры города является необходимым для дальнейшей разработки колористических решений города. От планировочной структуры, а также пространственной организации города зависит и структура его колористики.

Для проведения исследования была выбрана натуральная система цвета NCS (Natural Color System) как наиболее распространённая среди архитекторов и дизайнеров и более естественная для восприятия её человеком [14].

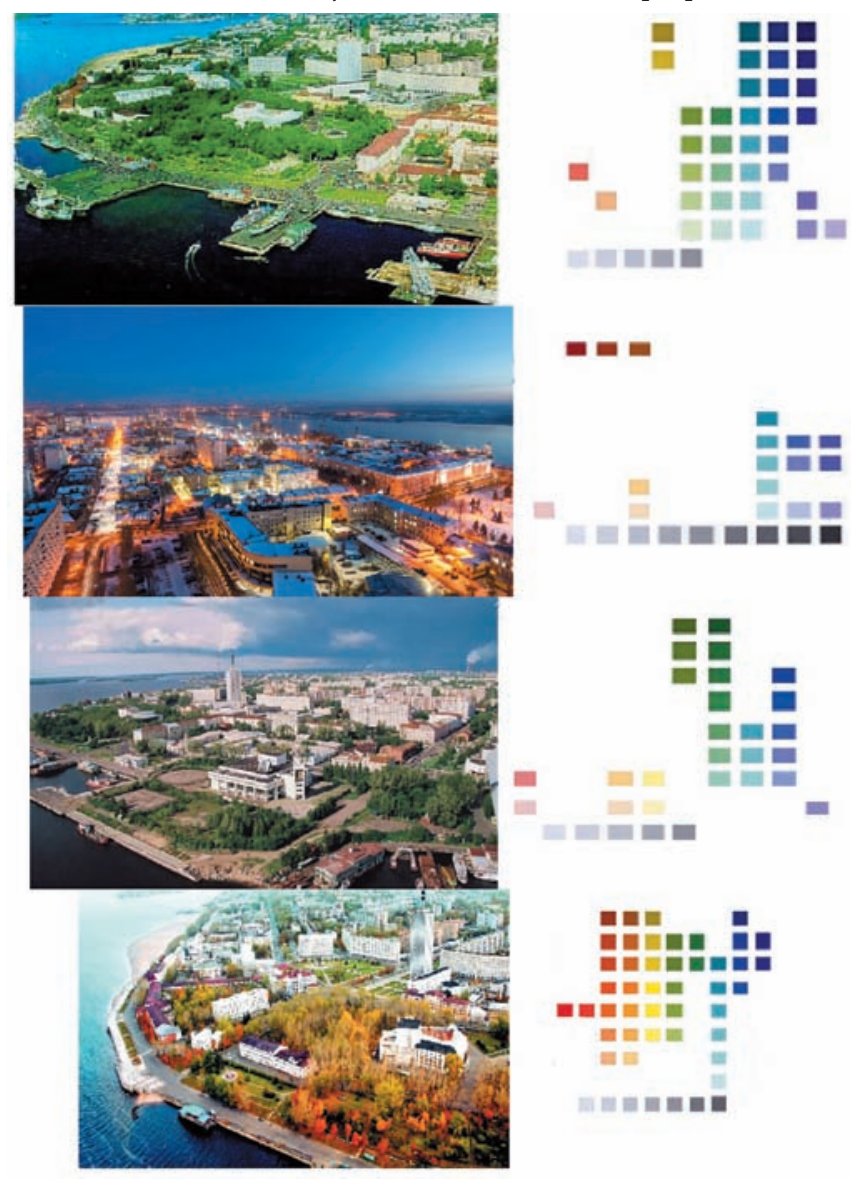

Pис. 1. Цветовая гамма городского пейзажа 
В ходе исследования цветовой среды города Архангельска установлена преобладающая цветность окружения в различные времена года. Доминирующие цвета, сформированные на основании палитры NCS в зависимости от сезонности, представлены на рисунке 1.

Согласно выработанным цветовым решениям доминирующая палитра цветов предполагает использование светлых оттенков, также используются ахроматические цвета. Указанные цветовые решения необходимо учитывать при планировании капитальных ремонтов фасадов существующих зданий и при новом строительстве.

В ходе проведённых исследований были разработаны рекомендации по созданию гармоничной цветовой городской

Таблица 1. Примеры цветовых сочетаний для объектов жилого назначения

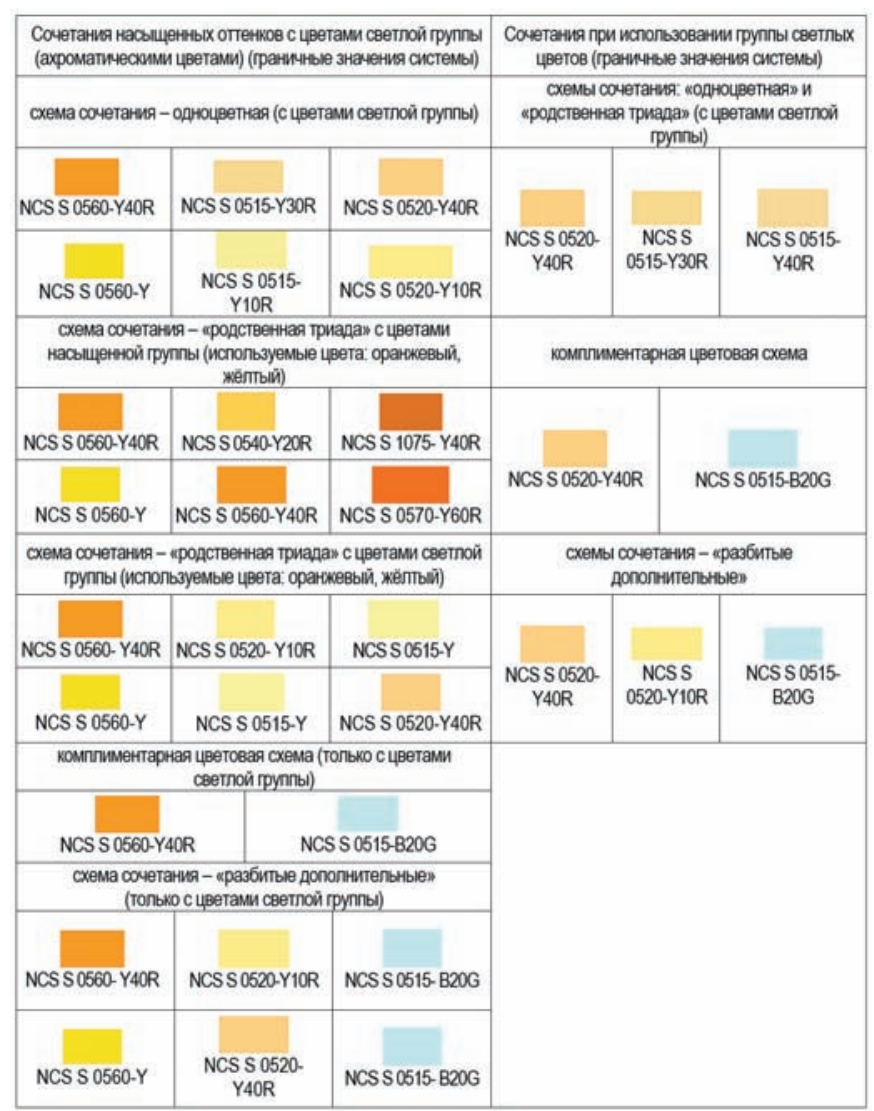

среды. В таблице 1 для примера представлены рекомендованные цветовые решения объектов жилого назначения, содержащие гармоничные сочетания цветов.

Гармоничные сочетания могут быть построены по многим схемам, но при выборе сочетаний в настоящем исследовании учтены основные, наиболее используемые:

1) одноцветная (монохроматическая) - использование нескольких оттенков одного цвета (контрастная или нюансная гармония);

2) гармония аналогичных цветов (родственная триада) - в данной цветовой схеме используются смежные цвета цветового круга и их смешение (нюансная гармония);

3) гармония дополнительных цветов (комплиментарная цветовая схема) - используются цвета, которые расположены напротив (контрастное сочетание);

4) разбитые дополнительные - это комплиментарная схема, но с одного конца она делится надвое, разбиваясь на два родственных цвета, дополнительных к третьему (контрастное сочетание);

5) триада равноудалённая - цвета лежат в вершинах равнобедренного треугольника на равном расстоянии друг от друга (контрастное сочетание).

На рисунке 2 приведён пример применения разработанной цветовой палитры для здания города Архангельска.

В ходе проведенного исследования установлены наиболее благоприятные цветовые решения при оформлении фасадов зданий в условиях городской конгломерации северных территорий. Так, с учётом исторически сложившейся колористической среды на примере различных районов города Архангельска, с учетом сезонности и природноклиматических особенностей, такими цветами являются оттенки светлых теплых тонов (желтый, оранжевый) в сочетании с оттенками холодных тонов разной насыщенности (серо-белая гамма).

Таким образом, внедрение в практику строительства системы регулирования на региональном и муниципальном уровне в части применения указанных цветовых решений повысит качество окружающей среды и комфортность проживания в северных городах.

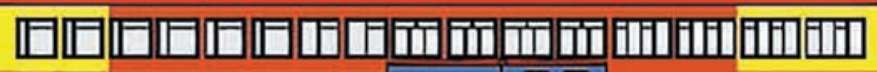

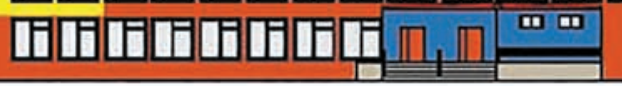
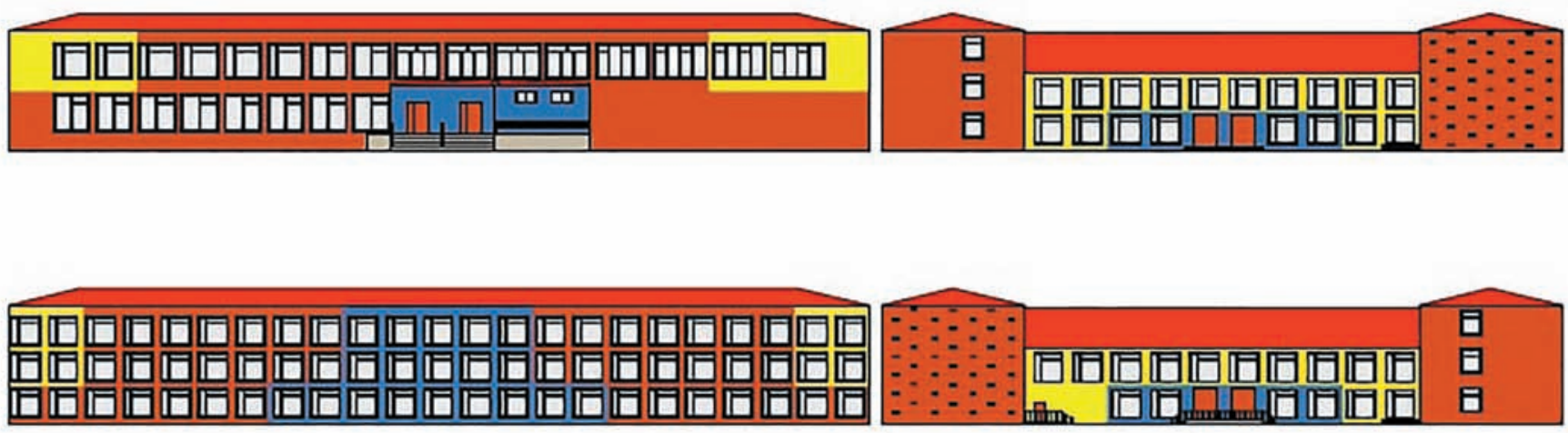

Рис. 2. Пример цветового решения здания общеобразовательного учреждения 


\section{Лuтература}

1. Фролова, М.А. Колористика как фактор архитектурной геоники для Северо-Арктического региона / М.А. Фролова, В.С. Лесовик // Материалы I всероссийской конференции с международным участием «Инновационные материалы и технологии для строительства в экстремальных климатических условиях». Архангельск, 2-4 декабря 2014 г. - Архангельск : Северный (Арктический) федеральный университет, 2014. - С. 201-206.

2. Мельнык, У.В. Цвет в дизайне городской среды [Электронный ресурс] /У.В. Мельнык // Вестник славянских культур, 2013. Режим доступа: http://www.vestnik-sk.ru/russian/archive/2013/4/ voprosyi-iskusstvovedeniya/melnyik (дата обращения: 31.03.2020).

3. Ефимов, A.В. Влияние полихромии на формообразование [Электронный ресурс] / А. В. Ефимов, Н. Г. Панова // Архитектура и современные информационные технологии. - 2014. - № 4 (29). - Режим доступа: http://www.marhi.ru/АMIT/2014/4kvart14/ efimov/abstract.php (дата обращения 15.02.2018).

4. Князева, А.С. Проблема формирования колористики главной улицы города (на примере улицы Мира в Красноярске) [электронный ресурс] / А.С. Князева // Молодёжь и наука : сборник материалов IX всероссийской научно-технической конференции студентов, аспирантов и молодых учёных с международным участием, посвящённой 385-летию со дня основания г. Красноярска. - Красноярск : Сибирский федеральный ун-т, 2013. - Режим доступа: http://conf.sfu-kras.ru/sites/ mn2013/thesis/s039/s039-007.pdf (дата обращения 10.03.2018).

5. Kristine J. Synnes, Anchorage, Alaska: Exploring Color in an Urban Frontier, [Электронный ресурс] / Kristine J. Synnes, René C. Akre // IAMNC Conference . - Anchorage, 2004. - Режим доступа: http://www.wintercities.com/Resources/articles/ Anchorage,\%20Alaska\%20Exloring\%20Color\%20in\%20an\%20 Urban\%20Frontier.pdf (дата обращения 01.10.2018).

6. Фролова, М.А. Колористика как фактор улучшения экологической ситуации северных городов (на примере Архангельска) [Электронный ресурс] / М.А. Фролова, Е.В. Гонтарь // Интеллектуальные строительные композиты для зелёного строительства : Сборник докладов международной научно-практической конференции, посвящённой 70-летию заслуженного деятеля науки РФ, члена-корреспондента РАACH, доктора технических наук, профессора Валерия Станиславовича Лесовика. В 3 частях. Белгородский государственный технологический университет им. В.Г. Шухова. 2016 - Белгород: Белгородский государственный технологический университет им. В.Г. Шухова. - Режим доступа: https://elibrary.ru/item. asp?id=26559273 (дата обращения 16.03.2018).

7. Агапов, Д.В. Проблемы сохранения деревянных конструкций зданий - объектов культурного наследия в г. Архангельске / Д.В. Агапов, М.В. Кошелева, Е.Н. Покровская // Сборник трудов 6-го Международного научно-практического симпозиума «Природные условия строительства и сохранения храмов Православной Руси». - Сергиев Посад, 2015. - С. 168-178.

8. Стенин, А.А. Минеральный модификатор поверхности строительных материалов из древесины / А.А. Стенин, А.М.
Айзенштадт, А.А. Шинкарук [и др.] // Строительные материалы. - 2014. - № 10. - С. 51-54.

9. Данилов, В.E. Конструкционная теплоизоляция на основе отходов деревообрабатывающей и горной промышленности / В.Е. Данилов, А.М. Айзенштадт, Т.А. Махова // Промышленное и гражданское строительство. - 2017. - № 1. - С. 97-100.

10. География и климат Архангельска [Электронный ресурс] // Архангельск. Официальный сайт. - Режим доступа: http://xn--80aajizflwo8a1f.su/priroda/geografia-climat/ (дата обращения 13.05.2018).

11. Цветовой потенциал исторической архитектуры Воронежа // ABIREG.RU. Агентство бизнес-информации. Режим доступа: https://abireg.ru/sb/print/n_36.html (дата обращения 01.07.2018).

12. Ефимов, А.В. Колористика города / А.В. Ефимов. - М. : Стройиздат, 1990. - 272 с.

13. Эволюция цветовых предпочтений [Электронный ресурс] // Dizayne.ru. - Режим доступа: http://www.dizayne.ru/ txt/3sozd0210.shtml (дата обращения 23.02.2018).

14. NCS - Natural Color System [Электронный ресурс] : [офиц. сайт]. - Режим доступа: http://ncscolour.ru/ncs/history/ свободный (дата обращения 31.01.2020) - Загл. с экрана.

\section{References}

1. Frolova M.A., Lesovik V.S. Koloristika kak faktor arkhitekturnoi geoniki dlya Severo-Arkticheskogo regiona [Coloristics as a factor of architectural geonics for the north-arctic region]. Materialy I vserossiiskoi konferentsii s mezhdunarodnym uchastiem "Innovatsionnye materialy $i$ tekhnologii dlya stroitel'stva $v$ ekstremal'nykh klimaticheskikh usloviyakh". Arkhangel'sk, 2-4 dekabrya 2014 g.) [Proceedings of the International Scientific Conference "Innovative materials and technologies for building industry in extreme climate"]. Arkhangel'sk : Severnyi (Arkticheskii) federal'nyi universitet Publ., 2014, pp. 201-206.

2. Mel'nyk, U. V. Tsvet $v$ dizaine gorodskoi sredy [Color in design of urban environment]. Vestnik slavyanskikh kul'tur [Bulletin of slavic cultures], 2013, no. 4. URL: http://www.vestniksk.ru/russian/archive/2013/4/voprosyi-iskusstvovedeniya/ melnyik (Accessed 31.01.2020).

3. Efimov A.V., Panova N.G. Vliyanie polikhromii na formoobrazovanie [The effect of polychromy on shaping]. Arkhitektura i sovremennye informatsionnye tekhnologii [Architecture and Modern Information Technologies], 2014, no. 4 (29). URL: http://www.marhi.ru/AMIT/2014/4kvart14/efimov/ abstract.php (Accessed 15.02.2018).

4. Knyazeva A.S. Problema formirovaniya koloristiki glavnoi ulitsy goroda (na primere ulitsy Mira v Krasnoyarske) [The problem of the formation of the color of the main street of the city (on the example of the street of Mir in Krasnoyarsk)]. Molodezh' $i$ nauka: sbornik materialov IX Vserossiiskoi nauchno-tekhnicheskoi konferentsii studentov, aspirantov i molodykh uchenykh s mezhdunarodnym uchastiem, posvyashchennoi 385-letiyu so dnya osnovaniya $g$. Krasnoyarska [Youth and Science : a collection of materials of the IX 
All-Russian scientific and technical conference of students, graduate students and young scientists with international participation, dedicated to the 385th anniversary of the founding of Krasnoyarsk]. Krasnoyarsk, Sibirskii federal'nyi un-t Publ., 2013. URL: http://conf. sfu-kras.ru/sites/mn2013/section039.html (Accessed 10.03.2018).

5. Kristine J. Synnes, René C. Akre. Anchorage, Alaska: Exploring Color in an Urban Frontier. IAMNC Conference . Anchorage, 2004. URL: http://wintercities.com/Resources/ articles/Anchorage,\%20Alaska \%20Exploring\%20Color $\% 20$ in\%20an\%20Urban\%20Frontier.pdf (Accessed 01.10.2018).

6. Frolova M.A., Gontar'E.V. Koloristika kak faktor uluchsheniya ekologicheskoi situatsii severnykh gorodov (na primere Arkhangel'ska) [Elektronnyi resurs] [Coloristics as a factor of improving the ecological situation of northern cities (on the example of Arkhangelsk)]. Intellektual'nye stroitel'nye kompozity dlya zelenogo stroitel'stva. Sbornik dokladov mezhdunarodnoi nauchno-prakticheskoi konferentsii, posvyashchennoi 70-letiyu zasluzhennogo deyatelya nauki RF, chlena-korrespondenta RAASN, doktora tekhnicheskikh nauk, professora Valeriya Stanislavovicha Lesovika: V 3 chastyakh. Belgorodskii gosudarstvennyi tekhnologicheskii universitet im. V.G. Shukhova [Intelligent building composites for green building. Collection of reports of the international scientific and practical conference dedicated to the 70th anniversary of the honored worker of science of the Russian Federation, corresponding member of RAASN, doctor of technical sciences, professor Valery Stanislavovich Lesovik: In 3 parts. Belgorod State Technological University. V.G. Shukhov, 2016. Belgorod: Belgorodskii gosudarstvennyi tekhnologicheskii universitet im. V.G. Shukhova Publ. URL: https:// elibrary.ru/item.asp?id=26559273 (Accessed 16.03.2018).

7. Agapov D.V., Kosheleva M.V., Pokrovskaya E.N. Problemy sokhraneniya derevyannykh konstruktsii zdanii - ob"ektov kul'turnogo naslediya v g.Arkhangel'ske [Problems of protection of wooden constructions of buildings - objects of cultural heritage in Arkhangelsk]. Sbornik trudov 6-go Mezhdunarodnogo nauchnoprakticheskogo Simpoziuma "Prirodnye usloviya stroitel'stva $i$ sokhraneniya khramov Pravoslavnoi Rusi" [Proceedings of the 6th International Scientific and Practical Symposium Natural Conditions for the Construction and Conservation of the Temples of Orthodox Russia]. Sergiev Posad, 2015, pp.168-178.

8. Stenin A.A., Aizenshtadt A.M., Shinkaruk A.A., Demidov M.L., Frolova M.A. Mineral'nyi modifikator poverkhnosti stroitel'nykh materialov iz drevesiny [Mineral modifier of the surface of building materials from wood]. Stroitel'nye materialy [Construction Materials], 2014, no. 10, pp. 51-54.

9. Danilov V.E., Aizenshtadt A.M. Makhova T.A. Konstruktsionnaya teploizolyatsiya na osnove otkhodov derevoobrabatyvayushchei i gornoi promyshlennosti [Structural insulation based on waste from the woodworking and mining industries]. Promyshlennoe i grazhdanskoe stroitel'stvo [Industrial and civil engineering], 2017. no. 1, pp. 97-100.

10. Geografiya i klimat Arkhangel'ska [Geography and climate of Arkhangelsk]. Arkhangel'sk. Ofitsial'nyi sait [Official website]. URL: http://xn--80aajizflwo8a1f.su/priroda/ geografia-climat/ (Accessed 13.05.2018).

11. Tsvetovoi potentsial istoricheskoi arkhitektury Voronezha [Color potential of historical architecture of Voronezh]. URL: https://abireg.ru/sb/print/n_36.html (Accessed 01.07.2018).

12. Efimov A.V. Koloristika goroda [Coloring of the city]. Moscow, Stroiizdat Publ., 1990, 272 p.

13. Evolyutsiya tsvetovykh predpochtenii [The evolution of color preferences]. Dizayne.ru. URL: http://www.dizayne.ru/ txt/3sozd0210.shtml (Accessed 23.02.2018).

14. NCS - Natural Color System : [ofits.sait]. URL: http:// ncscolour.ru/ncs/history/ svobodnyi (Accessed 31.01.2020).

Гонтарь Елена Владимировна (Архангельск). Аспирантка ФГАОУ В0 «Северный (Арктический) федеральный университет имени М.В. Ломоносова» (163002, Архангельск, набережная Северной Двины, д. 17ю САФУ им. М.В. Ломоносова). Эл.почта: e.tyulneva@mail.ru

Туробова Мария Александровна (Архангельск). Аспирантка ФГАОУ В0 «Северный (Арктический) федеральный университет имени М.В. Ломоносова» (163002, Архангельск, набережная Северной Двины, д. 17. САФУ им. М.В. Ломоносова). Эл.почта: turobowa.m@yandex.ru.

Фролова Мария Аркадьевна (Архангельск). Аспирантка ФГАОУ В0 «Северный (Арктический) федеральный университет имени М.В. Ломоносова» (163002, Архангельск, набережная Северной Двины, д. 17. САФУ им. М.В. Ломоносова). Эл.почта: aizenmaria@gmail.com.

Gontar Elena Vladimirovna (Arkhangelsk). Post-graduate student of Northern (Arctic) Federal University named after M.V. Lomonosov (17 Severnaya Dvina Emb., Arkhangelsk, 163002, NArFU). E-mail: e.tyulneva@mail.ru

Turobova Maria Alexandrovna (Arkhangelsk). Post-graduate student of Northern (Arctic) Federal University named after M.V. Lomonosov (17 Severnaya Dvina Emb., Arkhangelsk, 163002, NArFU). E-mail: turobowa.m@yandex.ru.

Frolova Maria Arkadievna (Arkhangelsk). Post-graduate student of Northern (Arctic) Federal University named after M.V. Lomonosov (17 Severnaya Dvina Emb., Arkhangelsk, 163002, NArFU). E-mail: aizenmaria@gmail.com. 